\title{
History of Atrial Fibrillation as a Risk Factor in Patients With Heart Failure and Preserved Ejection Fraction
}

\author{
Oludamilola W. Oluleye, MD, MPH; Thomas S. Rector, PhD; Sithu Win, MD; \\ John J.V. McMurray, MD; Michael R. Zile, MD; Michel Komajda, MD;
}

Robert S. McKelvie, MD, PhD; Barry Massie, MD; Peter E. Carson, MD; Inder S. Anand, MD, FRCP

Background - Atrial fibrillation (AFib) is common in heart failure (HF) with preserved ejection fraction (HFpEF). Current AFib stroke risk prediction models include the presence of HF but do not specifically include HFpEF as a risk factor. Whether a history of AFib should be used to identify patients with HFpEF who are at risk has not been established.

Methods and Results - Baseline characteristics and outcomes of patients with HFpEF in the Irbesartan in Heart Failure with Preserved Ejection Fraction Trial were analyzed in relation to AFib. At baseline, 1209 (29.3\%) had a history of AFib. Of these $557(13.5 \%)$ had history of AFib alone, whereas 670 (16.2\%) had both a history and AFib on ECG; 2901 (70.3\%) had neither. There were no significant differences in the risk of stroke between the 2 groups with a history of AFib who did or did not have AFib present on baseline ECG. During a median follow-up of 53 months, a fatal or nonfatal stroke occurred in 6.5\% (79/1209) patients with history of AFib compared with 3.9\% (114/2901) with no AFib. Having a history of AFib was independently associated with higher risk of stroke (hazard ratio, 2.2; 95\% confidence interval, 1.6-3.2; $P<0.0001$ ) compared with those with no history of AFib.

Conclusions - In patients with HFpEF, a history of AFib was common and independently associated with increased risk of stroke, regardless of whether AFib was present on ECG. Patients with HFpEF and a history of AFib should be considered at risk. Further studies are needed to determine whether this risk can be safely reduced.

Clinical Trial Registration_URL: http://www.clinicaltrials.gov. Unique identifier: NCT000095238.

(Circ Heart Fail. 2014;7:960-966.)

Key Words: atrial fibrillation $\boldsymbol{\square}$ heart failure $\boldsymbol{\square}$ preserved ejection fraction $\boldsymbol{\square}$ prognosis $\boldsymbol{\square}$ stroke

\begin{abstract}
A trial fibrillation (AFib) is the most common arrhythmia and is responsible for significant morbidity and mortality in patients with heart failure (HF) with reduced ejection fraction (HFrEF) or preserved ejection fraction (HFpEF). ${ }^{1,2}$ There is a reciprocal relationship between $\mathrm{HF}$ and AFib in which $\mathrm{HF}$ predisposes to AFib and AFib worsens $\mathrm{HF}^{3-5}$ Much is known about the role of AFib in HFrEF but studies of AFib in HFpEF are more limited. Some recent clinical trial and observational studies have shown that AFib is present in $\leq 43 \%$ of patients with $\mathrm{HFpEF}$ and is perhaps more prevalent than in HFrEF., ${ }^{2,3,5-8}$
\end{abstract}

\section{Clinical Perspective on p 966}

Studies of patients with HFpEF have shown that the presence of AFib on an ECG is independently associated with a higher incidence of cardiovascular morbidity. ${ }^{2,7}$
Recent studies have indicated that periodic ECGs may miss several patients who are at risk from AFib. ${ }^{9,10}$ A history of AFib may help identify some of these at-risk patients. The primary objective of this post hoc analysis of data from the Irbesartan in Heart Failure with Preserved Ejection Fraction Trial (I-PRESERVE) was to determine whether a history of AFib is an independent risk factor for stroke in patients with HFpEF.

\section{Methods}

\section{Study Design and Patient Selection}

I-PRESERVE is a randomized, placebo-controlled, double-blind, multicenter trial that enrolled subjects with symptomatic HFpEF to evaluate the efficacy of the angiotensin receptor blocker irbesartan. ${ }^{11}$ Briefly, 4128 patients, $\geq 60$ years with symptomatic (New York Heart Association class II-IV) HF with a left ventricular (LV) ejection

Received March 20, 2014; accepted August 21, 2014.

From the Department of Medicine, VA Medical Center and University of Minnesota, Minneapolis (O.W.O., T.S.R., S.W., I.S.A.); Institute of Cardiovascular and Medical Sciences, British Heart Foundation Glasgow Cardiovascular Research Centre, Glasgow, United Kingdom (J.J.V.M.); Department of Medicine, RHJ Department of Veterans Affairs Medical Center, Medical University of South Carolina, Charleston (M.R.Z.); Institut de Cardiologie, Université Paris 6, Pitie Salpetriere Hospital, Paris, France (M.K.); Department of Medicine, Population Health Research Institute, McMaster University, Hamilton, Ontario, Canada (R.S.M.); Department of Medicine, San Francisco Veterans Affairs Medical Center, University of California (B.M.); and Department of Medicine, Washington VAMC and Georgetown University, Washington, DC (P.E.C.).

Guest Editor for this article was Douglas L. Mann, MD.

Correspondence to Inder S. Anand, MD, DPhil (Oxon.), VA Medical Center, Cardiology 111-C, One Veterans Dr, Minneapolis, MN 55417. E-mail anand001@umn.edu

(C) 2014 American Heart Association, Inc.

Circ Heart Fail is available at http://circheartfailure.ahajournals.org 
fraction $>45 \%$, and $\geq 1$ hospitalization for HF during the previous 6 months were eligible to be enrolled. Patients who had not been hospitalized were required to have ongoing class III or IV symptoms with corroborative evidence of $\mathrm{HF}$, or a likely substrate for HFpEF, such as electrocardiographic or echocardiographic evidence of moderate or severe LV hypertrophy or left atrial enlargement in the absence of AFib. The primary end point of the study was the composite of all-cause mortality and protocol-specified cardiovascular hospitalizations. There were several secondary end points including all-cause mortality, cardiovascular death or HF hospitalization, and HF death or HF hospitalization (HF composite end point). Deaths and hospitalizations were adjudicated by a blinded independent end point committee, using prespecified criteria. Eligible patients were randomized to receive irbesartan or placebo in a 1:1 ratio stratified by site and use of an angiotensin-converting enzyme inhibitor at baseline. The study was approved by the institutional review board at each center, and all subjects provided a written informed consent.

This analysis focused on patients classified as at risk based on the history of AFib in the case report forms with or without AFib documented on the required baseline ECG. The following study outcomes were analyzed in these groups and compared with the group that had neither a history or ECG indicating AFib: fatal or nonfatal stroke, cardiovascular death or HF hospitalization, HF death or HF hospitalization, and all-cause mortality.

\section{Statistical Analysis}

The baseline characteristics of subjects with a history of AFib with or without AFib at baseline on their ECG and those without any indication of AFib were compared with each other using ANOVA for continuous variables or cross-tabulation for categorical variables with a Bonferroni correction for multiple pairwise comparisons when the overall $P$ value was significant. Distributions of the natriuretic peptide levels were positively skewed and were transformed using logarithms for analysis. Unadjusted Kaplan-Meier curves are shown to describe the study outcomes in each group. Because the investigational medication, irbesartan did not have a significant effect on any of the study end points, all enrolled subjects were included in this analysis.

Cox regression analyses were used to estimate hazard ratios for each of the study outcomes for the 2 distinct groups with a history of AFib, those with or without AFib also present on their baseline ECG, as well as both of these groups combined compared with the group with no history or ECG record of having AFib. The 2 groups with a history of AFib were compared with each other by simply changing the reference group for the AFib group indicator variable in the Cox regression analyses. Because all but 18 (2.7\%) of the 670 subjects that had AFib on their baseline ECG also had a history of AFib, we included these 18 patients whose history was most likely misclassified in the group with both a history of AFib and AFib on ECG. The results were not substantially different when these 18 subjects were excluded from all groups (not reported). Adjusted hazard ratios were estimated by multivariable Cox regression including age at baseline, sex, race, history of ischemic heart disease, chronic obstructive pulmonary disease, hypertension, hyperlipidemia, stroke, renal artery disease, diabetes mellitus, hospitalization for HF in previous 6 months, heart block, and other arrhythmias, chronic kidney disease, anemia, systolic blood pressure, LV hypertrophy on ECG, albumin, platelet count, and treatment with irbesartan, antiarrhythmic, antiplatelet agent, antithrombotic agent, calcium channel blocker, $\beta$-blocker, angiotensin-converting enzyme inhibitor, digoxin, diuretic, spironolactone, nitrate, lipid-lowering drugs, and an implantable cardioverter defibrillator/pacemaker. Several clinical variables that could be affected by the presence of ongoing AFib at baseline including pulmonary congestion on $\mathrm{x}$ ray, rales, jugular venous distention, liver enlargement, New York Heart Association class, heart rate, and natriuretic peptide were not included in these multivariable regression analyses to avoid over adjustment for potential mediators of the effects of AFib on study outcomes. The proportional hazards assumption for each variable and outcome was examined using Schoenfeld residuals. Stata software version 12.1 was used for all analyses.

\section{Results}

\section{Baseline Characteristics in Relation to AFib Indicators}

A history of AFib was present in 29\% (1209/4128) of the patients, and in approximately half of these (670/1209) AFib was documented on baseline ECG. There was no history or ECG documentation of AFib in 2901 of the 4128 patients.

Baseline characteristics of the 3 groups defined by AFib indicators are summarized in Table 1 . The groups with or without AFib on their baseline ECG were similar except for several signs and symptoms of decompensated HF, cardiac rhythm disturbances, ischemic heart disease, and medications. Both groups with indicators of AFib differed from those without AFib on several variables.

\section{Association Between Indicators of AFib and Outcomes}

During a median follow-up of 53 months (interquartile range, 41-60 months), fatal or nonfatal stroke occurred in 5.7\% (38/670) patients with history and AFib on ECG compared with 7.4\% (41/557) with history of AFib alone and in 3.9\% (114/2901) with no AFib (Figure [A]), cardiovascular death or HF hospitalization occurred in 45\% (302/670) patients with history and AFib on ECG compared with 54\% (298/557) with history of AFib alone and in 35\% (1021/2901) with no AFib (Figure [B]); the HF death or HF hospitalization composite end point occurred in 29\% (196/670) patients with history and AFib on ECG compared with 26\% (146/557) with history of AFib alone and in 13\% (367/2901) with no AFib (Figure [C]); 30\% (203/670) patients with history and ECG evidence of AFib died from any cause compared with $28 \%$ (156/557) with history of AFib alone and 18\% (515/2901) with no AFib (Figure [D]).

Table 2 shows the unadjusted and adjusted comparisons of study outcomes in AFib indicator groups. Except for a higher risk of HF hospitalizations or death in the group with AFib on baseline ECG, there were no significant differences in the outcomes between the $2 \mathrm{AFib}$ groups defined by ECG. As shown in Table 1, the group with AFib on baseline ECG had more signs and symptoms of $\mathrm{HF}$ as expected and these variables were not included in the adjustment model (see Statistical Analysis section). The increased risk of stroke was significant and similar in the groups with or without AFib on the baseline ECG. Combining these 2 groups, the adjusted estimate of the increase in the risk of fatal or nonfatal stroke associated with a history of AFib was hazard ratio 2.2 (95\% confidence interval, 1.6-3.2) compared with the group with no indication of AFib. A history of AFib was significantly associated with cardiovascular death or HF hospitalization, 1.2 (1.0-1.4) and HF death or HF hospitalization $1.3(1.1-1.6)$ but not with all-cause mortality.

\section{Discussion}

In this analysis of I-PRESERVE we found that although 29\% patients had a history of AFib at baseline, AFib was confirmed on ECG in only half (54\%) of them (16\% of total cohort), and the remaining patients (14\% of the cohort) had a history of AFib alone. The presence of AFib on the baseline ECG did not increase the significant risk of stroke associated with a history of AFib. To the best of our knowledge this is the first report to 
Table 1. Baseline Characteristics in Groups With and Without Indicators of Atrial Fibrillation

\begin{tabular}{|c|c|c|c|c|c|}
\hline & \multirow[b]{2}{*}{ None } & \multirow[b]{2}{*}{ History Only } & \multirow[b]{2}{*}{ History and ECG } & \multicolumn{2}{|c|}{$P$ Value } \\
\hline & & & & Overall & AFib Groups` \\
\hline No. of subjects & $2901(70 \%)$ & $557(14 \%)$ & $670(16 \%)$ & $\ldots$ & $\ldots$ \\
\hline Age, mean (SD), y & $71(6.8)$ & $73(6.6)$ & $74(7.1)$ & $<0.0001$ & NS \\
\hline Men, n (\%) & $1091(38)$ & $238(43)$ & $308(46)$ & $<0.0001$ & NS \\
\hline Nonwhite (\%) & 92 & 97 & 97 & $<0.0001$ & NS \\
\hline Hypertension, n (\%) & $2609(90)$ & $480(86)$ & $561(84)$ & $<0.0001$ & NS \\
\hline Diabetes mellitus, n (\%) & $785(27)$ & $159(29)$ & $182(28)$ & 0.73 & ND \\
\hline Hyperlipidemia, n (\%) & $1328(46)$ & $255(46)$ & $227(34)$ & $<0.0001$ & $<0.0001$ \\
\hline Ischemic heart disease, n (\%) & $1565(54)$ & $274(50)$ & $257(39)$ & $<0.0001$ & $<0.0001$ \\
\hline Stroke/TIA, n (\%) & $243(8.4)$ & $75(14)$ & $81(12)$ & $<0.0001$ & NS \\
\hline Renal artery disease (\%) & 10.2 & 3.0 & 2.4 & 0.002 & NS \\
\hline COPD/asthma, n (\%) & 237 (8.2) & $87(16)$ & $67(10)$ & $<0.0001$ & 0.009 \\
\hline Valve disease, $\mathrm{n}(\%)$ & $216(7.5)$ & $109(20)$ & $126(19)$ & $<0.0001$ & NS \\
\hline Other arrhythmia, n (\%) & $337(12)$ & $99(18)$ & $57(8.5)$ & $<0.0001$ & $<0.0001$ \\
\hline Heart block, n (\%) & $54(1.9)$ & $30(5.4)$ & $16(2.4)$ & $<0.0001$ & 0.02 \\
\hline Pacemaker/ICD implanted, n (\%) & $102(3.5)$ & $91(16)$ & $71(11)$ & $<0.0001$ & 0.04 \\
\hline HF admission in past 6 mo for HF, $\mathrm{n}(\%)$ & $1073(37)$ & $332(60)$ & $411(62)$ & $<0.0001$ & NS \\
\hline Hypertensive HF etiology, n (\%) & $1933(66.6)$ & $320(58)$ & $359(55)$ & $<0.0001$ & NS \\
\hline Ischemic HF etiology, $\mathrm{n}(\%)$ & $771(27)$ & $135(24)$ & $130(19)$ & 0.001 & NS \\
\hline Diastolic blood pressure, mean (SD), mm Hg & $79(8.9)$ & $77(9.5)$ & $79(9.4)$ & 0.0003 & NS \\
\hline Systolic blood pressure, mean (SD), mm Hg & $137(14)$ & $136(17)$ & $134(15)$ & $<0.0001$ & NS \\
\hline Heart rate, mean (SD) & $71(9.8)$ & $70(11)$ & $76(12)$ & $<0.0001$ & $<0.0001$ \\
\hline JVD, n (\%) & $204(7.0)$ & $39(7.0)$ & $103(16)$ & $<0.0001$ & $<0.0001$ \\
\hline Liver enlargement, $n(\%)$ & $533(18)$ & $81(14)$ & $139(21)$ & 0.014 & 0.015 \\
\hline Rales, n (\%) & $790(27)$ & $142(25)$ & $226(34)$ & 0.002 & 0.006 \\
\hline Left ventricular hypertrophy, n (\%) & $938(32)$ & $163(29)$ & $159(24)$ & $<0.0001$ & NS \\
\hline Left bundle-branch block, n (\%) & $244(8.4)$ & $48(8.6)$ & $44(6.6)$ & 0.28 & ND \\
\hline Pulmonary congestion on chest radiograph, $\mathrm{n}(\%)$ & $999(36)$ & $244(45)$ & $347(54)$ & $<0.0001$ & 0.006 \\
\hline Left ventricle EF \%, mean (SD) & $60(9.1)$ & $59(8.9)$ & $58(9.3)$ & $<0.0001$ & NS \\
\hline Left atrial area, $\mathrm{cm}^{2}$, mean $(\mathrm{SD}) \dagger$ & $21.3(5.0)$ & $25.3(6.6)$ & $29.7(6.3)$ & $<0.0001$ & $<0.0001$ \\
\hline eGFR, mean (SD), $\mathrm{mL} / \mathrm{min}$ & $74(22)$ & $69(23)$ & $69(21)$ & $<0.0001$ & NS \\
\hline CKD, n (\%) & $795(27.7)$ & $219(40.0)$ & $229(35.7)$ & $<0.0001$ & NS \\
\hline NT-proBNP, median (IQR), pg/mL & $230(104-538)$ & $534(232-1118)$ & 1319 (776-2062) & $<0.0001$ & $<0.0001$ \\
\hline Irbesartan, n (\%) & $1455(50)$ & $267(48)$ & $345(51)$ & 0.37 & ND \\
\hline ACE inhibitor, $\mathrm{n}(\%)$ & $696(24)$ & $154(28)$ & $183(27)$ & 0.08 & ND \\
\hline Antiplatelet, n (\%) & $1893(65)$ & $294(53)$ & $229(34)$ & $<0.0001$ & $<0.0001$ \\
\hline Antiarrhythmic, n (\%) & $99(3.4)$ & $178(32)$ & $82(12)$ & $<0.0001$ & $<0.0001$ \\
\hline Anticoagulant, n (\%) & $128(4.4)$ & $230(41)$ & $432(64)$ & $<0.0001$ & $<0.0001$ \\
\hline$\beta$-blocker, n (\%) & $1714(59)$ & $321(58)$ & $392(58)$ & 0.80 & ND \\
\hline Calcium channel blocker, n (\%) & $1221(42)$ & $194(35)$ & $222(33)$ & $<0.0001$ & NS \\
\hline Diuretic, n (\%) & $2307(80)$ & $485(87)$ & $626(93)$ & $<0.0001$ & $<0.0001$ \\
\hline Lipid lowering, n (\%) & $936(32)$ & $174(31)$ & $169(25)$ & 0.002 & NS \\
\hline Digoxin, n (\%) & $131(4.5)$ & $108(19)$ & $322(48)$ & $<0.0001$ & $<0.0001$ \\
\hline Nitrate, n (\%) & $828(29)$ & $134(24)$ & $146(22)$ & 0.001 & NS \\
\hline Spironolactone, n (\%) & $358(12)$ & $110(20)$ & $165(25)$ & $<0.0001$ & NS \\
\hline
\end{tabular}

ACE indicates angiotensin-converting enzyme; AFib, atrial fibrillation; COPD, chronic obstructive pulmonary disease; CKD, chronic kidney disease; eGFR, estimated glomerular filtration rate; EF, ejection fraction; HF, heart failure; ICD, implantable cardioverter defibrillator; IQR, interquartile range; JVD, jugular venous distension; ND, not done because overall not significant; NS, not significant with Bonferroni correction for possible 3 pairwise comparisons; NT-proBNP, N-terminal pro B natriuretic peptide; and TIA, transient ischemic attack.

${ }^{*}$ Comparing the 2 groups that did or did not have AFib on baseline ECG if overall ANOVA P value was $<0.01$.

†Left atrial area was measured in 696 subjects only. 
A
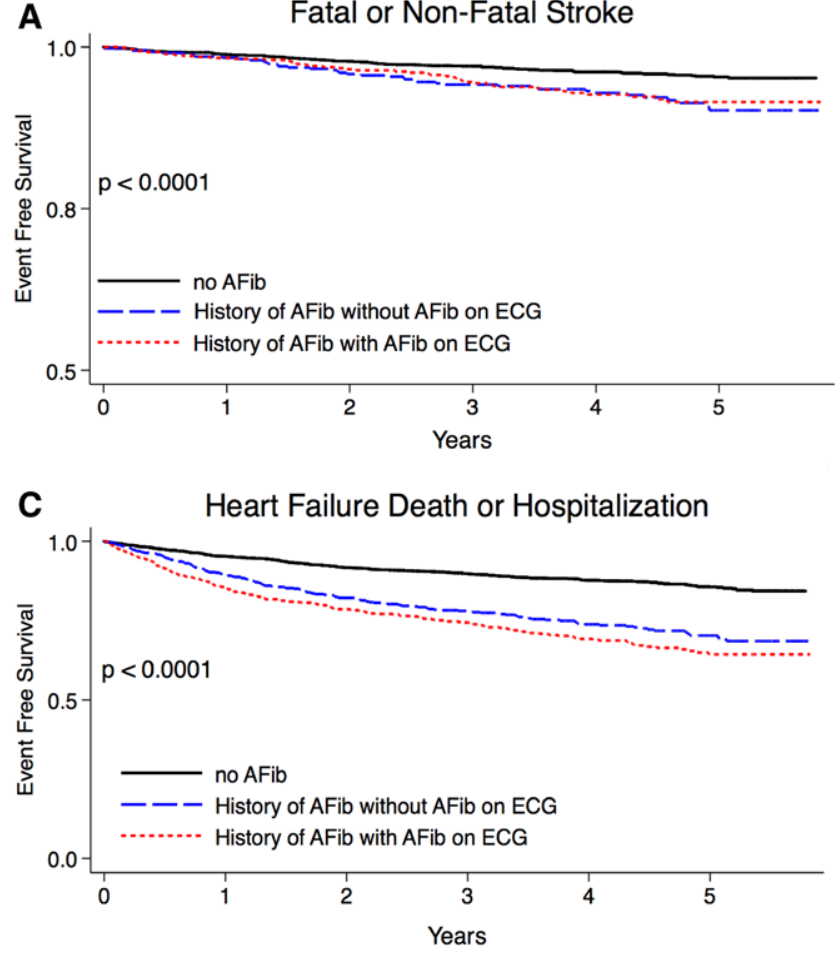

B Cardiovascular Death or HF Hospitalization

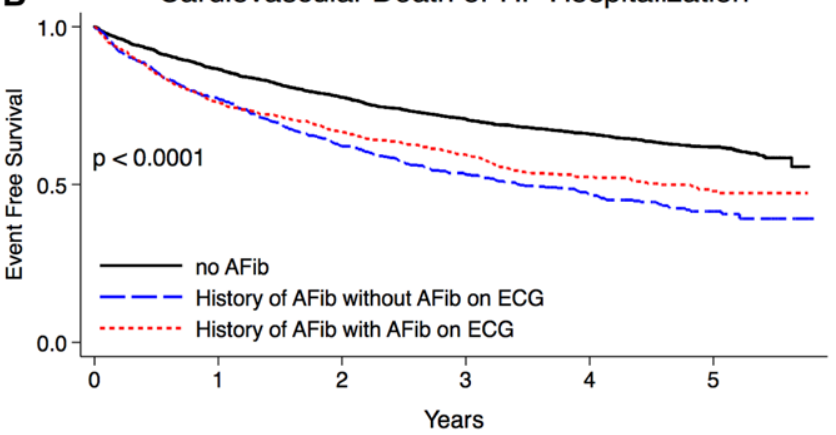

D All-Cause Mortality

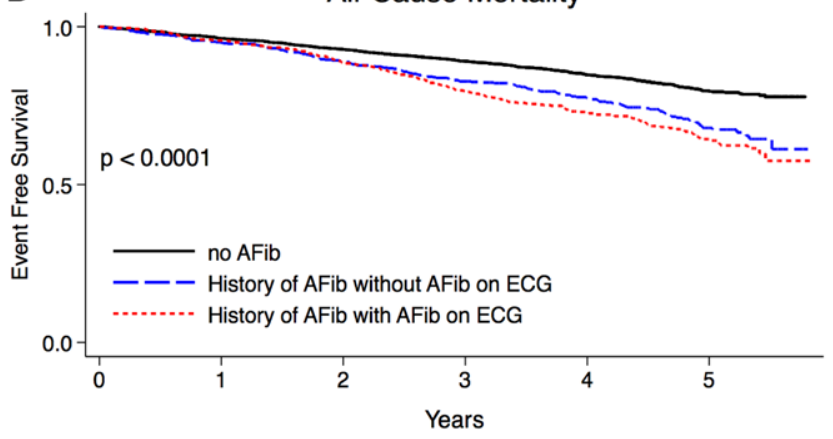

Figure. Kaplan-Meier curves for time to fatal or nonfatal stroke (A), cardiovascular death or heart failure (HF) hospitalization (B), HF death or HF hospitalization (C), and all-cause mortality (D) in groups defined by a history of atrial fibrillation (AFib), a history of AFib confirmed by ECG or no indication of AFib.

highlight this finding in patients with HFpEF. Although the risk associated with AFib on ECG in patients with HFpEF has been examined previously, ${ }^{2,7,12-15}$ this analysis indicates that a history of AFib is also associated with an increased risk of cardiovascular morbidity and mortality, including stroke. These results, therefore, suggest that a history of AFib should be taken into consideration when assessing the risks of AFib in patients with HFpEF regardless of whether AFib is present on ECG.

Although it is well known that AFib increases the risk of ischemic stroke in patients with HFrEF, only a few recent studies have reported that the risk of stroke is also increased in patients with HFpEF.,2,12-14,16 Studies have compared the risk of stroke in patients with AFib and HFrEF or HFpEF. A subgroup analysis of the AFib Follow up Investigation of Rhythm Management (AFFIRM) trial found that although the history of stroke was more prevalent in patients with HFpEF compared with HFrEF at baseline (16\% versus $11 \%$ ), the subsequent incidence of stroke during the study was no different between the groups. ${ }^{17}$ The Candesartan in Heart failure-Assessment of Reduction in Mortality and morbidity (CHARM) study also did not find a difference in the incidence of stroke in patients with AFib with either $\mathrm{HFrEF}$ or $\mathrm{HFpEF}^{7}$ In patients with preexisting AFib, McManus et $\mathrm{al}^{2}$ reported a $91 \%$ higher risk of ischemic stroke in $\mathrm{HFpEF}$ and only $7 \%$ higher risk in HFrEF compared with those without AFib. The most recent data come from the post hoc analyses of the new oral anticoagulant trials such as ARISTOTLE (Apixaban for Reduction in Stroke and Other Thromboembolic Events in Atrial Fibrillation Trial), ${ }^{12}$ ROCKET (Rivaroxaban Once daily oral direct factor Xa inhibition Compared with vitamin $\mathrm{K}$ antagonism for prevention of stroke and Embolism Trial in atrial fibrillation), ${ }^{13}$ and RE-LY (Randomized Evaluation of
Long-term anticoagulation therapY with dabigatran etexilate).$^{14}$ These studies show that although the risk of stroke or systemic embolism was significantly higher in patients with a diagnosis of HF compared with those with no HF, the risk of stroke or systemic embolism was no different in patients with HF with preserved or reduced ejection fraction. These data suggest that the risk of stroke in patients with $\mathrm{AFib}$ and $\mathrm{HFpEF}$ is at least as high as those in patients with AFib and HFrEF and that the guidelines should specifically emphasize the inclusion of all patients with HF in the CHADS2 (congestive HF, hypertension, age, diabetes mellitus, and prior stroke or transient ischemic attack) and CHA2DS2-VASc scoring system, irrespective of the ejection fraction. Furthermore, our data suggest that the same guidelines should also apply to patients with HFpEF even when they only have a history of AFib that is not confirmed on ECG.

The original $\mathrm{CHADS}_{2}$ score designed to help estimate the risk of stroke and need of anticoagulation in patients with nonvalvular AFib was based on studies in patients with HF with LV dysfunction. ${ }^{18}$ Accordingly, the 2006 and 2011 American College of Cardiology/American Heart Association/Heart Rhythm Society AFib clinical practice guidelines recommended the use of $\mathrm{CHADS}_{2}$ score as a guide to anticoagulation of patients with AFib and HF with impaired LV systolic function but did not mention HFpEF. 19,20 The most recent European Society of Cardiology AFib 2012 guidelines recommend the use of $\mathrm{CHA}_{2} \mathrm{DS}_{2}$-VASc instead of the $\mathrm{CHADS}_{2}$ score and define $\mathrm{HF}$ as documented moderate-to-severe systolic dysfunction or patients with recent decompensated heart failure requiring hospitalization, irrespective of ejection fraction but do not include stable patients with HFpEF. ${ }^{21}$ The 2 most recent HF guidelines also do not specifically mention HFpEF. The 
Table 2. Comparison of Outcomes in Atrial Fibrillation Indicator Groups

\begin{tabular}{|c|c|c|}
\hline Outcome & Unadjusted HR (95\% Cl; n=4128) & Adjusted* HR (95\% Cl; $\mathrm{n}=3942)$ \\
\hline \multicolumn{3}{|l|}{ Fatal or nonfatal stroke } \\
\hline History of AFib without AFib on ECG & 1.00 (reference group) & 1.00 (reference group) \\
\hline History of AFib with AFib on ECG & $0.94(0.62-1.44)$ & $1.16(0.72-1.86)$ \\
\hline No AFib on history or baseline ECG & 1.00 (reference group) & 1.00 (reference group) \\
\hline History of AFib without AFib on ECG & $1.97(1.38-2.81)$ & $2.12(1.40-3.21) \dagger$ \\
\hline History of AFib with AFib on ECG & $1.85(1.31-2.61)$ & $2.45(1.54-3.92) \dagger$ \\
\hline Combined groups with history of AFib & $1.90(1.44-2.52) \dagger$ & $2.24(1.55-3.24) \dagger$ \\
\hline \multicolumn{3}{|l|}{ CV death/HF hospitalization } \\
\hline History of AFib without AFib on ECG & 1.00 (reference group) & 1.00 (reference group) \\
\hline History of AFib with AFib on ECG & $0.86(0.73-1.00)$ & $0.92(0.76-1.09)$ \\
\hline No AFib on history or baseline ECG & 1.00 (reference group) & 1.00 (reference group) \\
\hline History of AFib without AFib on ECG & $1.81(1.59-2.06) \dagger$ & $1.23(1.05-1.44) \ddagger$ \\
\hline History of AFib with AFib on ECG & $1.55(1.36-1.76) \dagger$ & $1.13(0.94-1.34)$ \\
\hline Combined groups with history of AFib & $1.67(1.51-1.84) \dagger$ & $1.19(1.03-1.37) \ddagger$ \\
\hline \multicolumn{3}{|l|}{ HF death/HF hospitalization } \\
\hline History of AFib without AFib on ECG & 1.00 (reference group) & 1.00 (reference group) \\
\hline History of AFib with AFib on ECG & $1.23(0.99-1.52)$ & $1.28(1.01-1.64) \ddagger$ \\
\hline No AFib on history or baseline ECG & 1.00 (reference group) & 1.00 (reference group) \\
\hline History of AFib without AFib on ECG & $2.29(1.89-2.78) \dagger$ & $1.18(0.93-1.50)$ \\
\hline History of AFib with AFib on ECG & $2.82(2.37-3.35) \dagger$ & $1.51(1.19-1.92) \ddagger$ \\
\hline Combined groups with history of AFib & $2.57(2.22-2.98) \dagger$ & $1.32(1.08-1.63) \ddagger$ \\
\hline \multicolumn{3}{|l|}{ All-cause mortality } \\
\hline History of AFib without AFib on ECG & 1.00 (reference group) & 1.00 (reference group) \\
\hline History of AFib with AFib on ECG & $1.18(0.96-1.45)$ & $1.14(0.90-1.44)$ \\
\hline No AFib on history or baseline ECG & 1.00 (reference group) & 1.00 (reference group) \\
\hline History of AFib without AFib on ECG & $1.66(1.39-1.98) \dagger$ & $1.07(0.86-1.34)$ \\
\hline History of AFib with AFib on ECG & $1.95(1.66-2.29) \dagger$ & $1.23(0.99-1.54)$ \\
\hline Combined groups with history of AFib & $1.82(1.59-2.06) \dagger$ & $1.15(0.95-1.38)$ \\
\hline
\end{tabular}

2012 European Society of Cardiology HF guideline endorses thromboembolic prophylaxis in patients with HF and AFib based on the $\mathrm{CHA}_{2} \mathrm{DS}_{2}$-VASc score, defining HF as congestive $\mathrm{HF}$ or $\mathrm{LV}$ ejection fraction $<40 \%,{ }^{22}$ and the most recent, 2013 American College of Cardiology Foundation/American Heart Association HF guideline recommends the use of anticoagulant in patients with chronic heart failure with permanent, persistent, or paroxysmal AF and an additional risk for cardioembolic stroke. ${ }^{1}$ Hence, although the intent of the guidelines might have been to include all patients with HF irrespective of LV ejection fraction, the written document may be ambiguous and clinicians may not be entirely clear on this issue.

\section{Strengths and Limitations}

This analysis is based on the largest randomized clinical trial of well-characterized patients with HFpEF where all outcomes were adjudicated. In addition, we were able to examine AFib separately by history alone and AFib confirmed by ECG along with several established prognostic variables, including comorbidities, clinical examination and laboratory data, and medication use. However, this is a secondary analysis of data from a randomized controlled trial and some of the findings may be spurious although the results are consistent with previous studies. The results may not be widely applicable. For example, I-PRESERVE subjects with HFpEF were predominantly white and the results may not be generalizable to other racial groups. The presence of AFib was assessed at baseline by a single ECG. However, this limitation is unlikely to change our conclusions because the outcomes were similar in those with history of AFib not confirmed on ECG. Indeed, a history of AFib seemed to be sufficient to increase the risk and captured nearly all of the patients with AFib on ECG. Because 
we did not have data on patients with HFrEF including sets of covariates, comparisons of the different types of HF could not be made as some previous studies have done.

In conclusion, in this sample of patients with HFpEF, a history of AFib was common and independently associated with increased risk of fatal or nonfatal stroke. The presence of AFib on ECG did not significantly heighten the risk. Patients with HFpEF and a history of AFib should be considered at risk of stroke, and HFpEF should be included as a risk factor in stroke prediction models for patients with AFib. Future studies are needed to determine whether this risk can be safely reduced.

\section{Sources of Funding}

Bristol-Myers Squibb sponsored the Irbesartan in Heart Failure with Preserved Ejection Fraction Trial (I-PRESERVE). Dr Rector was supported by resources and facilities of the Minneapolis VA Healthcare System. The views expressed herein do not necessarily represent the views of the Department of Veterans Affairs or the US Government.

\section{Disclosures}

Drs McMurray, Zile, Komajda, McKelvie, Massie, Carson, and Anand were consultant to Bristol-Myers Squibb. The other authors report no conflicts.

\section{References}

1. Yancy CW, Jessup M, Bozkurt B, Butler J, Casey DE Jr, Drazner MH, Fonarow GC, Geraci SA, Horwich T, Januzzi JL, Johnson MR, Kasper EK, Levy WC, Masoudi FA, McBride PE, McMurray JJ, Mitchell JE, Peterson PN, Riegel B, Sam F, Stevenson LW, Tang WH, Tsai EJ, Wilkoff BL; American College of Cardiology Foundation; American Heart Association Task Force on Practice Guidelines. 2013 ACCF/AHA guideline for the management of heart failure: a report of the American College of Cardiology Foundation/American Heart Association Task Force on Practice Guidelines. J Am Coll Cardiol. 2013;62:e147-e239.

2. McManus DD, Hsu G, Sung SH, Saczynski JS, Smith DH, Magid DJ, Gurwitz JH, Goldberg RJ, Go AS; Cardiovascular Research Network PRESERVE Study. Atrial fibrillation and outcomes in heart failure with preserved versus reduced left ventricular ejection fraction. J Am Heart Assoc. 2013;2:e005694.

3. Tsang TS, Gersh BJ, Appleton CP, Tajik AJ, Barnes ME, Bailey KR, Oh JK, Leibson C, Montgomery SC, Seward JB. Left ventricular diastolic dysfunction as a predictor of the first diagnosed nonvalvular atrial fibrillation in 840 elderly men and women. J Am Coll Cardiol. 2002;40:1636-1644.

4. Maisel WH, Stevenson LW. Atrial fibrillation in heart failure: epidemiology, pathophysiology, and rationale for therapy. Am J Cardiol. 2003;91:2D-8D.

5. Wang TJ, Larson MG, Levy D, Vasan RS, Leip EP, Wolf PA, D’Agostino RB, Murabito JM, Kannel WB, Benjamin EJ. Temporal relations of atrial fibrillation and congestive heart failure and their joint influence on mortality: the Framingham Heart Study. Circulation. 2003;107:2920-2925.

6. Klapholz M, Maurer M, Lowe AM, Messineo F, Meisner JS, Mitchell J, Kalman J, Phillips RA, Steingart R, Brown EJ Jr, Berkowitz R, Moskowitz R, Soni A, Mancini D, Bijou R, Sehhat K, Varshneya N, Kukin M, Katz SD, Sleeper LA, Le Jemtel TH; New York Heart Failure Consortium. Hospitalization for heart failure in the presence of a normal left ventricular ejection fraction: results of the New York Heart Failure Registry. J Am Coll Cardiol. 2004;43:1432-1438.

7. Olsson LG, Swedberg K, Ducharme A, Granger CB, Michelson EL, McMurray JJ, Puu M, Yusuf S, Pfeffer MA; CHARM Investigators. Atrial fibrillation and risk of clinical events in chronic heart failure with and without left ventricular systolic dysfunction: results from the Candesartan in Heart failure-Assessment of Reduction in Mortality and morbidity (CHARM) program. J Am Coll Cardiol. 2006;47:1997-2004.

8. Shah SJ, Heitner JF, Sweitzer NK, Anand IS, Kim HY, Harty B, Boineau R, Clausell N, Desai AS, Diaz R, Fleg JL, Gordeev I, Lewis EF, Markov V, O’Meara E, Kobulia B, Shaburishvili T, Solomon SD, Pitt B, Pfeffer MA, Li R. Baseline characteristics of patients in the treatment of preserved cardiac function heart failure with an aldosterone antagonist trial. Circ Heart Fail. 2013;6:184-192.

9. Healey JS, Connolly SJ, Gold MR, Israel CW, Van Gelder IC, Capucci A, Lau CP, Fain E, Yang S, Bailleul C, Morillo CA, Carlson M, Themeles E, Kaufman ES, Hohnloser SH; ASSERT Investigators. Subclinical atrial fibrillation and the risk of stroke. N Engl J Med. 2012;366:120-129.

10. Charitos EI, Pürerfellner H, Glotzer TV, Ziegler PD. Clinical classifications of atrial fibrillation poorly reflect its temporal persistence: insights from 1,195 patients continuously monitored with implantable devices. $J$ Am Coll Cardiol. 2014;63(25 Pt A):2840-2848.

11. Massie BM, Carson PE, McMurray JJ, Komajda M, McKelvie R, Zile MR, Anderson S, Donovan M, Iverson E, Staiger C, Ptaszynska A; I-PRESERVE Investigators. Irbesartan in patients with heart failure and preserved ejection fraction. $N$ Engl J Med. 2008;359:2456-2467.

12. McMurray JJ, Ezekowitz JA, Lewis BS, Gersh BJ, van Diepen S, Amerena J, Bartunek J, Commerford P, Oh BH, Harjola VP, Al-Khatib SM, Hanna M, Alexander JH, Lopes RD, Wojdyla DM, Wallentin L, Granger CB; ARISTOTLE Committees and Investigators. Left ventricular systolic dysfunction, heart failure, and the risk of stroke and systemic embolism in patients with atrial fibrillation: insights from the ARISTOTLE trial. Circ Heart Fail. 2013;6:451-460.

13. van Diepen S, Hellkamp AS, Patel MR, Becker RC, Breithardt G, Hacke W, Halperin JL, Hankey GJ, Nessel CC, Singer DE, Berkowitz SD, Califf RM, Fox KA, Mahaffey KW. Efficacy and safety of rivaroxaban in patients with heart failure and nonvalvular atrial fibrillation: insights from ROCKET AF. Circ Heart Fail. 2013;6:740-747.

14. Ferreira J, Ezekowitz MD, Connolly SJ, Brueckmann M, Fraessdorf M, Reilly PA, Yusuf S, Wallentin L; RE-LY Investigators. Dabigatran compared with warfarin in patients with atrial fibrillation and symptomatic heart failure: a subgroup analysis of the RE-LY trial. Eur J Heart Fail. 2013;15:1053-1061.

15. Linssen GC, Rienstra M, Jaarsma T, Voors AA, van Gelder IC, Hillege HL, van Veldhuisen DJ. Clinical and prognostic effects of atrial fibrillation in heart failure patients with reduced and preserved left ventricular ejection fraction. Eur J Heart Fail. 2011;13:1111-1120.

16. Jang SJ, Kim MS, Park HJ, Han S, Kang DH, Song JK, Park SW, Park SJ, Kim JJ. Impact of heart failure with normal ejection fraction on the occurrence of ischaemic stroke in patients with atrial fibrillation. Heart. 2013;99:17-21.

17. Badheka AO, Rathod A, Kizilbash MA, Bhardwaj A, Ali O, Afonso L, Jacob S. Comparison of mortality and morbidity in patients with atrial fibrillation and heart failure with preserved versus decreased left ventricular ejection fraction. Am J Cardiol. 2011;108:1283-1288.

18. Gage BF, van Walraven C, Pearce L, Hart RG, Koudstaal PJ, Boode BS, Petersen P. Selecting patients with atrial fibrillation for anticoagulation: stroke risk stratification in patients taking aspirin. Circulation. 2004;110:2287-2292.

19. Fuster V, Rydén LE, Cannom DS, Crijns HJ, Curtis AB, Ellenbogen KA, Halperin JL, Le Heuzey JY, Kay GN, Lowe JE, Olsson SB, Prystowsky EN, Tamargo JL, Wann S, Smith SC Jr, Jacobs AK, Adams CD, Anderson JL, Antman EM, Halperin JL, Hunt SA, Nishimura R, Ornato JP, Page RL, Riegel B, Priori SG, Blanc JJ, Budaj A, Camm AJ, Dean V, Deckers JW, Despres C, Dickstein K, Lekakis J, McGregor K, Metra M, Morais J, Osterspey A, Tamargo JL, Zamorano JL; American College of Cardiology; American Heart Association Task Force; European Society of Cardiology Committee for Practice Guidelines; European Heart Rhythm Association; Heart Rhythm Society. ACC/AHA/ESC 2006 guidelines for the management of patients with atrial fibrillation: full text: a report of the American College of Cardiology/American Heart Association Task Force on practice guidelines and the European Society of Cardiology Committee for Practice Guidelines (Writing Committee to Revise the 2001 guidelines for the management of patients with atrial fibrillation) developed in collaboration with the European Heart Rhythm Association and the Heart Rhythm Society. Europace. 2006;8:651-745.

20. Fuster V, Rydén LE, Cannom DS, Crijns HJ, Curtis AB, Ellenbogen KA, Halperin JL, Kay GN, Le Huezey JY, Lowe JE, Olsson SB, Prystowsky EN, Tamargo JL, Wann LS. 2011 ACCF/AHA/HRS focused updates incorporated into the ACC/AHA/ESC 2006 Guidelines for the management of patients with atrial fibrillation: a report of the American College of Cardiology Foundation/American Heart Association Task Force on Practice Guidelines developed in partnership with the European Society of Cardiology and in collaboration with the European Heart Rhythm Association and the Heart Rhythm Society. J Am Coll Cardiol. 2011;57:e101-e198.

21. Camm AJ, Lip GY, De Caterina R, Savelieva I, Atar D, Hohnloser SH, Hindricks G, Kirchhof P; ESC Committee for Practice Guidelines-CPG; 
Document Reviewers. 2012 focused update of the ESC Guidelines for the management of atrial fibrillation: an update of the 2010 ESC Guidelines for the management of atrial fibrillation-developed with the special contribution of the European Heart Rhythm Association. Europace. 2012;14:1385-1413.

22. McMurray JJ, Adamopoulos S, Anker SD, Auricchio A, Böhm M, Dickstein K, Falk V, Filippatos G, Fonseca C, Gomez-Sanchez MA, Jaarsma T, Køber L, Lip GY, Maggioni AP, Parkhomenko A, Pieske
BM, Popescu BA, Rønnevik PK, Rutten FH, Schwitter J, Seferovic P, Stepinska J, Trindade PT, Voors AA, Zannad F, Zeiher A; ESC Committee for Practice Guidelines. ESC Guidelines for the diagnosis and treatment of acute and chronic heart failure 2012: The Task Force for the Diagnosis and Treatment of Acute and Chronic Heart Failure 2012 of the European Society of Cardiology. Developed in collaboration with the Heart Failure Association (HFA) of the ESC. Eur Heart J. 2012;33:1787-1847.

\section{CLINICAL PERSPECTIVE}

Atrial fibrillation (AFib) is common in patients with heart failure (HF) and reduced or preserved ejection fraction. The current AFib stroke risk prediction guidelines include the presence of HF but do not specifically mention HF with preserved ejection fraction as a risk factor. Moreover, most risk assessment studies have used ECG to identify patients with AFib. Whether a history of AFib should also be used to identify patients with HF with preserved ejection fraction who are at risk from AFib has not been established. Our analysis of the 4128 patients in Irbesartan in Heart Failure with Preserved Ejection Fraction Trial (I-PRESERVE) showed that $29 \%$ of the patients had a history of AFib, whereas only $16 \%$ had both a history and AFib on ECG. There were no significant differences in the risk of stroke between the 2 groups with a history of AFib. A history of AFib was independently associated with $>2$-fold increase in the risk of stroke, regardless of whether AFib was present on ECG. Patients with HF with preserved ejection fraction and a history of AFib should be considered at risk. Further studies are needed to determine whether this risk can be safely reduced. 


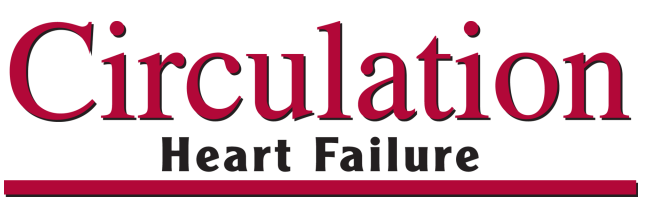

American

Heart

Association $_{\circledast}$

\section{History of Atrial Fibrillation as a Risk Factor in Patients With Heart Failure and Preserved Ejection Fraction}

Oludamilola W. Oluleye, Thomas S. Rector, Sithu Win, John J.V. McMurray, Michael R. Zile, Michel Komajda, Robert S. McKelvie, Barry Massie, Peter E. Carson and Inder S. Anand

Circ Heart Fail. 2014;7:960-966; originally published online September 15, 2014;

doi: 10.1161/CIRCHEARTFAILURE.114.001523

Circulation: Heart Failure is published by the American Heart Association, 7272 Greenville Avenue, Dallas, TX 75231

Copyright (C) 2014 American Heart Association, Inc. All rights reserved.

Print ISSN: 1941-3289. Online ISSN: 1941-3297

The online version of this article, along with updated information and services, is located on the World Wide Web at:

http://circheartfailure.ahajournals.org/content/7/6/960

\footnotetext{
Permissions: Requests for permissions to reproduce figures, tables, or portions of articles originally published in Circulation: Heart Failure can be obtained via RightsLink, a service of the Copyright Clearance Center, not the Editorial Office. Once the online version of the published article for which permission is being requested is located, click Request Permissions in the middle column of the Web page under Services. Further information about this process is available in the Permissions and Rights Question and Answer document.
}

Reprints: Information about reprints can be found online at: http://www.lww.com/reprints

Subscriptions: Information about subscribing to Circulation: Heart Failure is online at: http://circheartfailure.ahajournals.org//subscriptions/ 